\title{
Wpływ kulowania na właściwości użytkowe połączeń spawanych stali austenitycznej 1.4539 wykonanych metodą TIG i wiązką lasera
}

\author{
Shot-peening effect of the welded joints properties \\ of the austenitic steel 1.4539 made by TIG and laser beam
}

\section{Streszczenie}

W pracy przedstawiono wpływ kulowania pneumatycznego powierzchni na strukturę, mikrotwardość i naprężenia własne połączeń wykonanych ze stali austenitycznej 1.4539 spawanej wiązką lasera $\mathrm{CO}_{2}$ i metodą TIG. Celem praktycznym badań było uzupełnienie obecnego stanu wiedzy dotyczącego połączeń spawanych laserowo i metodą TIG umocnionych kulowaniem powierzchni. Badania wykazały znaczne rozdrobnienie struktury powierzchni połączeń spawanych oraz wzrost mikrotwardości i naprężeń ściskających.

Słowa kluczowe: kulowanie, stal austenityczna, TIG, laser

\section{Abstract}

This article presents shot-peening effect on the structure, microhardness and compressive of the austenitic steel 1.4539 welded by TIG and $\mathrm{CO}_{2}$ laser beam. Practical research aim is to supplement current state of knowledge and practice of the welded joints of the austenitic steel 1.4539 made by TIG and laser beam which is reinforced by shot-peening. The research shows significant defragmentation of the welded connections structure, microhardness and compressive stress increase.

Keywords: austen itic stainless steel, shot peening, TIG, laser beam

\section{Przedmiot badań}

Przedmiotem badań była stal austenityczna 1.4539

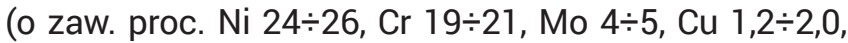
$\mathrm{Mn} \leq 2,0, \mathrm{~N} \leq 0,15, \mathrm{Si} \leq 0,7, \mathrm{P} \leq 0,030, \mathrm{~S} \leq 0,010, \mathrm{C} \leq 0,02$ ) spawana metodą TIG oraz laserowo. Połączenie nietopliwą elektrodą wolframową $\$ 2,5 \mathrm{~mm}$ MTC MT-904L i spoiwem G/W $20255 \mathrm{CuL}(20 \% \mathrm{Cr}, 25 \% \mathrm{Ni}, 4,5 \% \mathrm{Mo}$, $1,5 \% \mathrm{Cu}$ ) zostało wykonane w Zakładach Budowy Aparatury Chemicznej, Grupa Azoty w Tarnowie wg technologii produkcyjnej stosowanej praktycznie do wykonania m.in. aparatury chemicznej (rys. 1a, b). Natomiast laserowe spawanie przeprowadzono w Centrum Laserowych Technologii Metali Politechniki Świętokrzyskiej za pomocą lasera $\mathrm{CO}_{2}$ TRIUMF 1005 w odległości ogniskowej soczewki $260 \mathrm{~mm}$ z plamką na powierzchni próbki $\Phi 0,4 \mathrm{~mm}$ o mocy $\mathrm{P}=4,5 \mathrm{~kW}$ i prędkości spawania $v=1,4 \mathrm{~m} / \mathrm{min}$, w osłonie helu (rys. $1 \mathrm{c}, \mathrm{d}$ ).

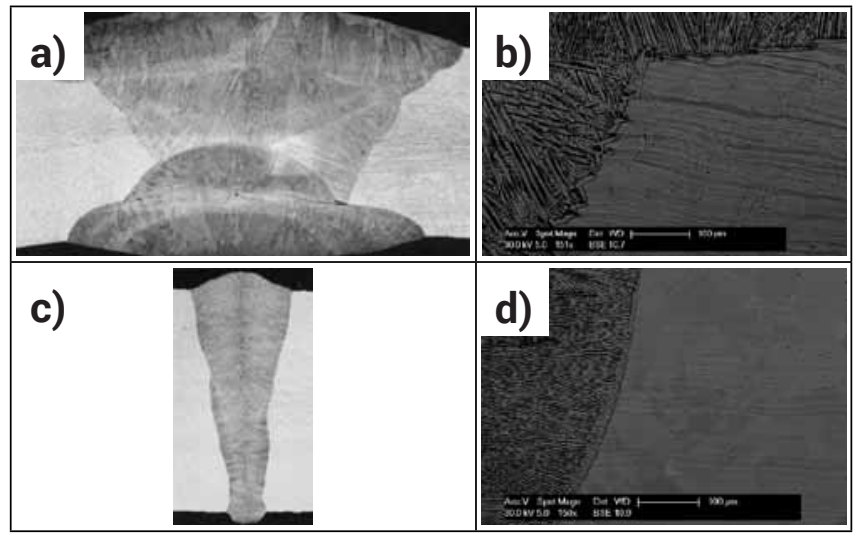

Rys. 1. Struktura spoiny wykonanej metodą TIG (a), (b) oraz laserem $\mathrm{CO}_{2}$ przy parametrach spawania $\mathrm{P}=4,5 \mathrm{~kW}$ i v $=1,4 \mathrm{~m} / \mathrm{min}$ (c), (d) Fig. 1. Weld structure made by $\mathrm{TIG}(\mathrm{a})$, (b) and $\mathrm{CO}_{2}$ laser beam with welding parameters $\mathrm{P}=4,5 \mathrm{~kW}$ i v $=1,4 \mathrm{~m} / \mathrm{min}(\mathrm{c}),(\mathrm{d})$

Mgr inż. Barbara Nasiłowska; dr hab. inż. Zdzisław Bogdanowicz, prof. WAT; - Wojskowa Akademia Techniczna inż. Grzegorz Mońka - Instytut Mechaniki Precyzyjnej; dr inż. Wojciech Szymański - Instytut Metali Nieżelaznych w Gliwicach 


\section{Wyniki badań}

Kulowanie warstwy wierzchniej połączeń spawanych ze stali 1.4539 wiązką lasera i metodą TIG zostato przeprowadzone w Instytucie Mechaniki Precyzyjnej w Warszawie (rys. 2a) strumieniem śrutu ze stali sprężynowej (ok. $640 \mathrm{HV}$ ) o średnicy $\Phi 0,8 \mathrm{~mm}$ pod ciśnieniem 0,5 atm. Czas trwania ekspozycji wynosił 6 min, zaś pokrycie próbki 100\%. Intensywność kulowania określona za pomocą płytki Almena Stripsa (typ $A$, grade II) wynosiła $f_{c}=0,25 \mathrm{~mm}$ (rys. $2 b$ ). Parametry takie stosowano dla wielu konstrukcji spawanych.
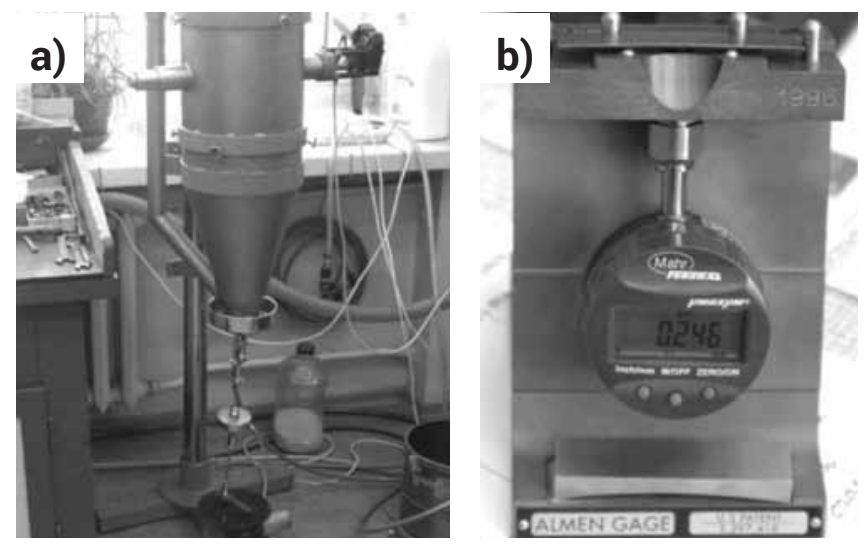

Rys. 2. Stanowisko do kulowania warstwy wierzchniej (a) oraz pomiar strzałki ugięcia płytki kontrolnej Almena (b)

Fig. 2. Workplace for top layer shot-peening (a) and Almen's control strip deflection measurement (b)

W wyniku kulowania (dynamicznego umacniania) warstwy wierzchniej stereometria powierzchni nie uległa znacznym zmianom (rys. 3). Chropowatość powierzchni przed kulowaniem wyniosła $R_{a}=3,9 \mu \mathrm{m}, R_{y 5}=18,53 \mu \mathrm{m}$, zaś po kulowaniu $R_{a}=3,98 \mu \mathrm{m}$ i $R_{y 5}=18,77 \mu \mathrm{m}$.
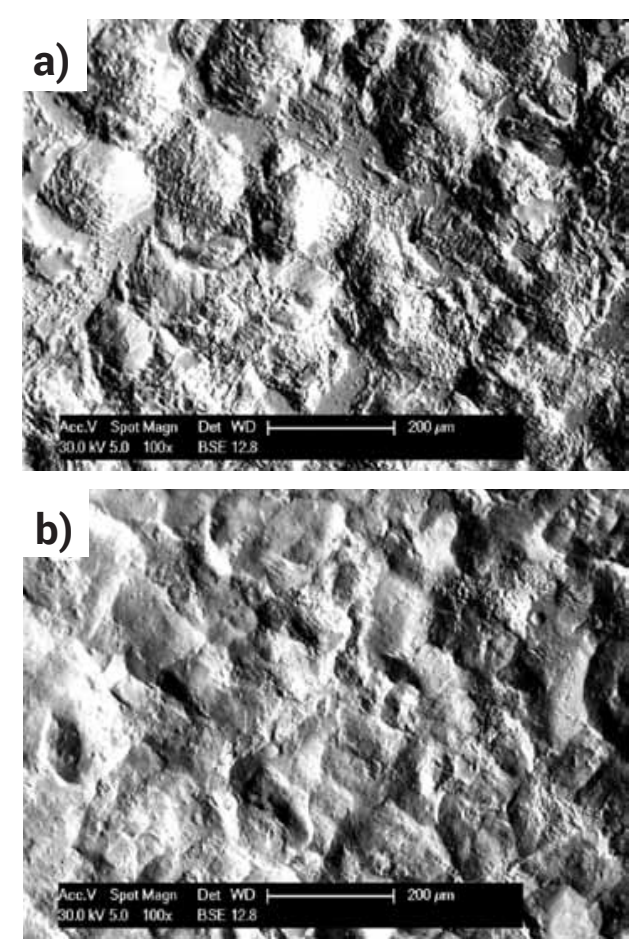

Rys. 3. Topografia powierzchni stali 1.4539 przed (a) i po kulowaniu (b) Fig. 3. 1.4539 steel surface topography before (a) and after (b) shotpeening
Badania wykonywane za pomoca elektronowego mikroskopu skaningowego struktury materiału rodzimego (rys. 4a, b) strefy złącza spawanego wiązką lasera (rys. 4c, d) i metodą TIG (rys. 4e, f) stali 1.4539 po kulowaniu wykazały deformację ziaren austenitu wywołanej zgniotem warstwy wierzchniej do głębokości $150 \div 200 \mu \mathrm{m}$.
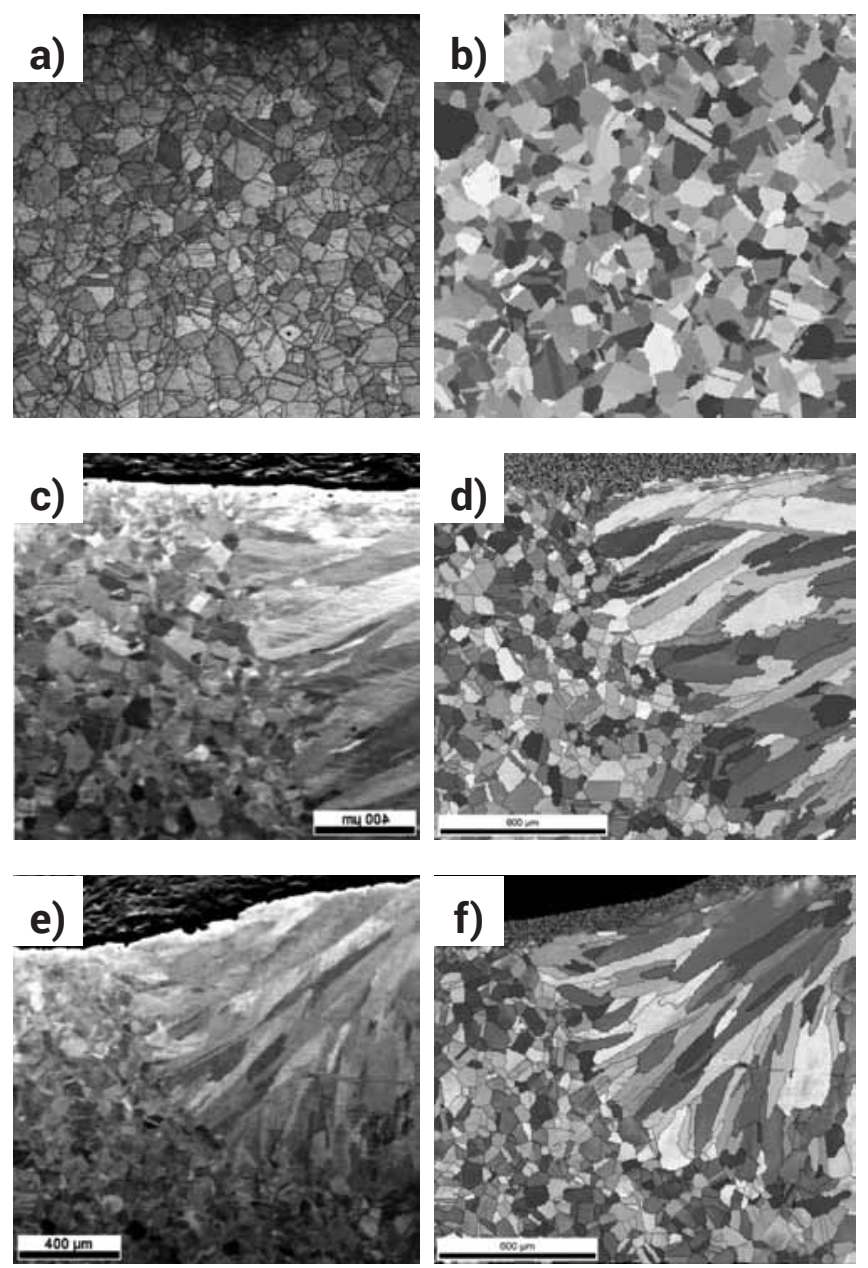

Rys. 4. Mikrostruktura warstwy wierzchniej po kulowaniu mechanicznym materiału rodzimego $(a, b)$ strefy połączeń spawanych wiązką lasera (c), (d) i metodą TIG (e), (f) wykonana przy użyciu mikroskopu skaningowego Quanta 3D FEG firmy FEl i detektora FSD $(a, c, e)$ oraz $\operatorname{EBSD}(b, d, f)$

Fig. 4. Top layer microstructure after shot-peening of the base material $(a, b)$ of the welds made by laser beam (c), (d) and TIG method (e), (f) made with Quanta 3D FEG FEI with FSD detector (a, c, e) and $\operatorname{EBSD}(b, d, f)$ scanning electron microscope

Pomiary mikrotwardości zostały wykonane metodą Vickersa HV0,1 przed umocnieniem i po umocnieniu w głąb powierzchni materiału rodzimego, w strefie wpływu ciepła (SWC) oraz w spoinie (S) próbek spawanych wiązką lasera i metodą TIG.

Efektem dynamicznej obróbki powierzchniowej połączeń spawanych jest umocnienie warstwy wierzchniej spowodowane zgniotem powierzchniowym. Wyniki badań rozkładu mikrotwardości przedstawione w formie wykresów dla próbek spawanych wiązką lasera (rys. 5) i metodą TIG (rys. 6) wskazują na znaczny wzrost mikrotwardości.

W wyniku obróbki plastycznej walcowaniem w procesie produkcyjnym stali 1.4539 mikrotwardość materiału rodzimego (MR) przed kulowaniem wynosiła 
ok. $290 \mathrm{HV}(20 \mu \mathrm{m}$ w głąb powierzchni), natomiast po umocnieniu dynamicznym wzrosła do ok. $350 \mathrm{HV}$ na tej samej głębokości.

Cykl cieplny w procesie spawania laserowego spowodował odpuszczenie i ponowny rozrost ziaren w postaci dendrytów, w wyniku czego mikrotwardość w strefie wpływu ciepła (SWC) i spoinie (S) przed kulowaniem ukształtowała się do wartości normatywnej (195 HV). Natomiast proces umacniania dynamicznego spowodował wzrost mikrotwardości do poziomu ok. $400 \mathrm{HV}$ w SWC i S na głębokości ok. $20 \mu \mathrm{m}$ od powierzchni próbki (rys. 5). Strefa połączenia spawanego wiązką lasera została umocniona na głębokości ok. $300 \mu \mathrm{m}$.

Wskutek cyklu cieplnego i segregacji pierwiastków stopowych wchodzących w skład spoiwa spoiny wykonanej metodą TIG mikrotwardość na głębokości $20 \mu \mathrm{m}$ od powierzchni próbki w osi spoiny przed kulowaniem wynosiła $154 \mathrm{HV}$ i przechodziła w wartość znormalizowaną na poziomie $195 \mu \mathrm{m}$.

W procesie kulowania mechanicznego nastąpito umocnienie warstwy wierzchniej do głębokości ok. $250 \mu \mathrm{m}$ (rys. 6).

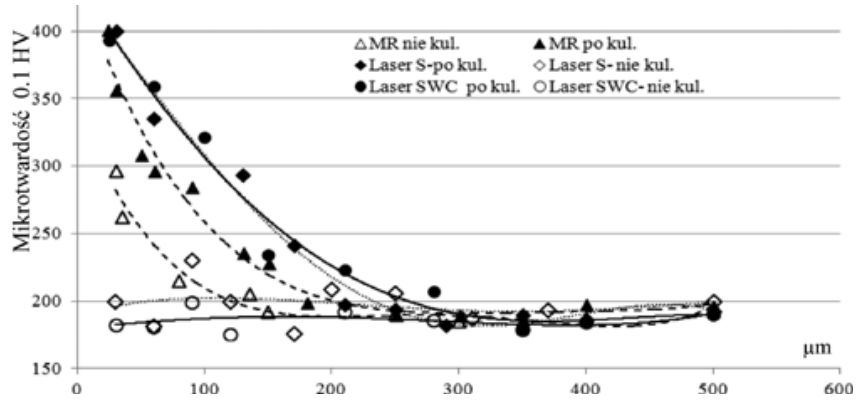

Rys. 5. Rozkład mikrotwardości w głąb warstwy wierzchniej materiału rodzimego i elementów spawanych wiązką lasera

Fig. 5. Distribution of microhardness into the top layer of the base metal and welds made by laser beam

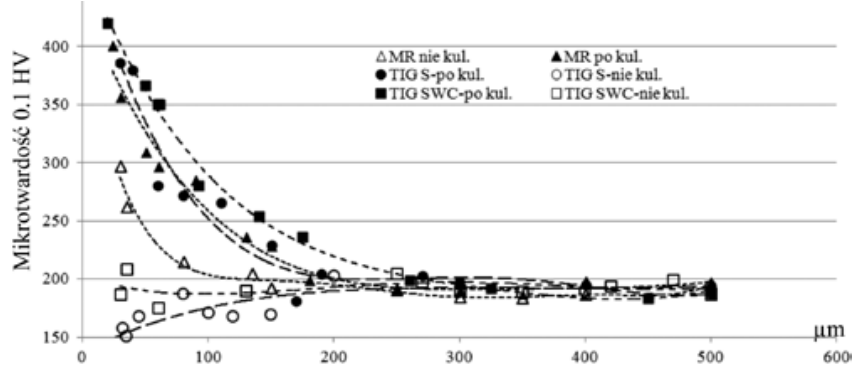

Rys. 6. Rozkład mikrotwardości w głąb warstwy wierzchniej materiału rodzimego i elementów spawanych metodą TIG

Fig. 6. Distribution of microhardness into the top layer of the base metal and welds made by TIG

\section{Badania doświadczalne naprężeń własnych połączeń spawanych}

Badania naprężeń własnych zostały wykonane w Instytucie Metali Nieżelaznych Oddział Metali Lekkich w Skawinie. Pomiary prowadzono w spoinie, strefie wpływu ciepła i materiale rodzimym przed i po kulowaniu połączeń wykonanych metodą TIG i wiązką lasera, w osi x i y (rys. 7). Badania wykonano przenośnym dyfraktometrem rentgenowskim PROTO i XRD do pomiaru naprężeń własnych i zawartości austenitu szczątkowego firmy PROTO, Kanada.

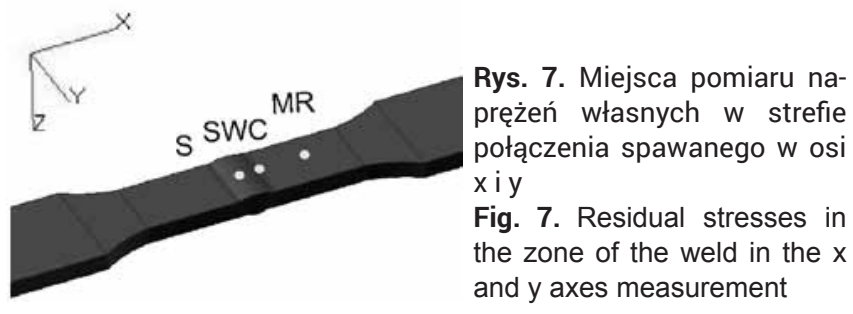

W analizowanych obszarach (S, SWC, MR) nastąpił wzrost naprężeń ściskających na powierzchni połączeń spawanych wiązką lasera i metodą TIG spowodowany kulowaniem (rys. 8). Głębiej położone warstwy metalu nie pozwalają na swobodne i pełne rozprzestrzenienie się odkształceń plastycznych wywołanych procesem kulowania, co w efekcie powoduje powstanie naprężeń ściskających [9].

W spoinie (S) stan naprężeń ściskających po kulowaniu zmieniał się od -364 do -661 MPa w zależności od metody wykonania i kierunków pomiarowych. Przed procesem kulowania w strefie wpływu ciepła (SWC) i spoinie (S) stwierdzono w tych strefach naprężenia własne rozciągające. Natomiast $w$ materiale rodzimym (MR) po spawaniu występowały w każdym przypadku naprężenia ściskające, których wartość wzrosła po procesie kulowania.

Największe naprężenia własne ściskające występują w SWC i MR dla połączenia laserowego po kulowaniu. W połączeniu wykonanym metodą TIG w SWC naprężenia po kulowaniu (większy efekt cieplny) wyniosły -295 MPa (x) i $81 \mathrm{MPa}(\mathrm{y})$.

a)

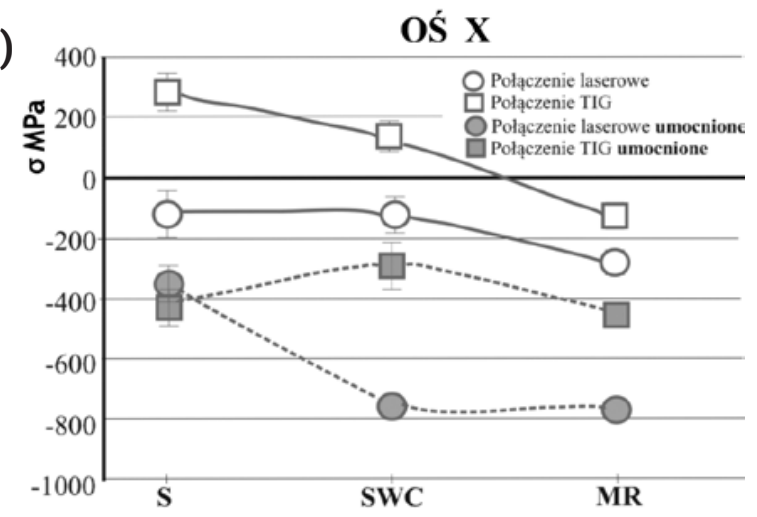

b)

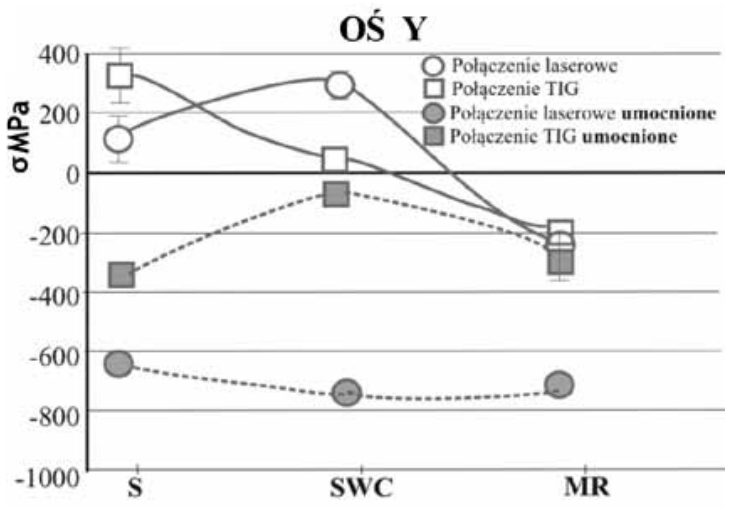

Rys. 8. Naprężenia własne w spoinie (S), strefie wpływu ciepła (SWC) oraz materiale rodzimym (MR) w osi x (a) i y (b) przed oraz po kulowaniu powierzchni

Fig. 8. Residual stresses in the joint (s), heat-affected zone (HAZ) and the base material (BM) in the X-axis (a) and Y-axis (b) before and after surface shot-peening measurement 


\section{Wnioski}

1. W wyniku kulowania warstwy wierzchniej chropowatość powierzchni uległa nieznacznym zmianom i wynosiła:

- przed kulowaniem $R_{a}=3,9 \mu \mathrm{m}, R_{y 5}=18,53 \mu \mathrm{m}$,

- po kulowaniu $R_{a}=3,98 \mu \mathrm{m}$ i $R_{y 5}=18,77 \mu \mathrm{m}$.

2. Głębokość umocnionego ww. materiału po kulowaniu sięgała odpowiednio do:

- $200 \mu \mathrm{m}$ dla materiału rodzimego,

- $250 \mu \mathrm{m}$ dla strefy wpływu ciepła (SWC) i spoiny

(S) wykonanej metodą TIG,

- $300 \mu \mathrm{m}$ dla strefy wpływu ciepła (SWC) i spoiny

(S) wykonanej laserowo.

W wyniku obróbki plastycznej materiału rodzimego (MR) walcowaniem mikrotwardość przed kulowaniem wynosiła ok. $290 \mathrm{HV}$ na głębokości $20 \mu \mathrm{m}$ od powierzchni. Natomiast po kulowaniu mikrotwardość ta wzrosła do ok. $350 \mathrm{HV}$.

3. Proces kulowania próbek spawanych laserowo spowodował wzrost mikrotwardości do wartości ok. $400 \mathrm{HV}$ na głębokości ok. $20 \mu \mathrm{m}$ od powierzchni próbki.

4. Rozkład mikrotwardości przed kulowaniem spoiny wykonanej metodą TIG na głębokości $20 \mu \mathrm{m}$ wyniósł $154 \mathrm{HV}$, przechodząc w wartość znormalizowaną na poziomie $195 \mu \mathrm{m}$. Po kulowaniu wystąpił wzrost mikrotwardości do poziomu ok. $420 \mathrm{HV}$ w SWC i S na głębokości ok. $20 \mu \mathrm{m}$ od powierzchni próbki.

5. Naprężenia ściskające prostopadle do osi spoiny w połączeniach spawanych wiązką lasera po kulowaniu znacząco wzrosły i wynosiły odpowiednio: - -364 MPa w spoinie (przed -121 MPa),

- -748 MPa w strefie wpływu ciepła (przed -129 MPa),

- -766 MPa w materiale rodzimym (przed $-279 \mathrm{MPa}$ ), natomiast równolegle do osi spoiny wynosiły:

- -661 MPa w spoinie (przed -117 MPa),

- -730 MPa w strefie wpływu ciepła (przed $296 \mathrm{MPa}$ ),

- -713 MPa materiale rodzimym (przed -250 MPa).

6. W połączeniach spawanych metodą TIG po kulowaniu również nastąpił wzrost naprężeń ściskających prostopadle do osi spoiny o:

- $-420 \mathrm{MPa}$ w spoinie (przed $282 \mathrm{MPa}$ ),

- -295 MPa w strefie wpływu ciepła (przed $123 \mathrm{MPa}$ ),

- $-445 \mathrm{MPa}$ w materiale rodzimym (przed -143 MPa).

oraz równolegle do osi spoiny:

$--356 \mathrm{MPa}$ w spoinie (przed $336 \mathrm{MPa}$ ),

- -81 MPa w strefie wpływu ciepła (przed $46 \mathrm{MPa}$ ),

- $-280 \mathrm{MPa}$ materiale rodzimym (przed $-230 \mathrm{MPa}$ ).

\section{Literatura}

[1] T. Burakowski, W. Napadłek: Umacnianie udarowe metali. Inżynieria Materiałowa Wydawnictw ISSN 0208-6247, 2008, Vol. 29, nr 6, s.1044-1046.

[2] A. Fedoryszyn, T. Piosik, S. Rzadkosz, L. Staszczak, P. Zyzak: Efekty obróbki powierzchniowej strumieniem śrutu. XII Konferencja Odlewnicza Technical 2010.

[3] K. Zhan, C.H. Jiang, V. Ji: Effect of prestress state on surface layer characteristic of S30432 austenitic stainless steel in shot peening process. Materials and Design 42 (2012), 89-93.

[4] K. Zhan, C.H. Jianga, V. Ji: Surface mechanical properties of S30432 austenitic steel after shot peening. Applied Surface Science 258 (2012), 9559-9563.

[5] K. Zhan a, C.H. Jiang V. Ji: Uniformity of residual stress distribution on the surface of S30432 austenitic stainless steel by different shot peening processes. Materials Letters 99 (2013), 61-64.
[6] L. Shen, L. Wang, Y. Wang, Ch. Wang: Plasma nitriding of AISI 304 austenitic stainless steel with pre-shot peening. Surface \& Coatings Technology 204 (2010), 3222-3227.

[7] O. Takakuwa, H. Soyama: Suppression of hydrogen-assisted fatigue crack growth in austenitic stainless steel by cavitation peening. International Journal of Hydrogen Energy 37 (2012), 5268-5276,

[8] K. Zhan, C.H. Jianga, V. Ji: Surface mechanical properties of S30432 austenitic steel after shot peening. Applied Surface Science 258 (2012), 9559- 9563.

[9] P. Fu, Ch. Jiang, Residual stress relaxation and micro-structural development of the surface layer of 18CrNiMo7-6 steel after shot peening during isothermal annealing. Materials and Design 56 (2014), 1034-1038. 